Original Article

\title{
Determination of the conceptual structures of the disturbed activities of daily living due to Katakori by evaluating patients' values or perceptions using a patient-elicitation technique
}

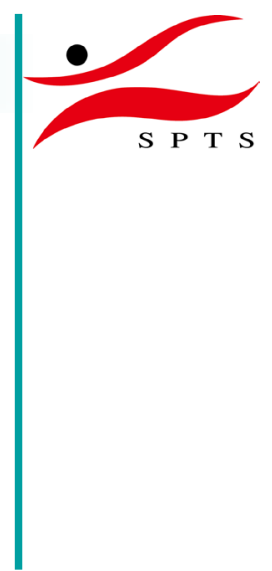

\author{
Kouhei Natsume ${ }^{1)}$, Yusuke Handa, BSc ${ }^{1)}$, Hiroshi Takasaki, PhD ${ }^{1)^{*}}$ \\ 1) Department of Physical Therapy, Saitama Prefectural University: 820 Sannomiya, Koshigaya, \\ Saitama 343-8540, Japan
}

\begin{abstract}
Purpose] To investigate the disturbed activities of daily living due to Katakori, a nonspecific symptom that includes discomfort or dull pain around the occiput through the cervical spine to the acromion and scapular area, by assessment of patients' values or perceptions. [Participants and Methods] Fifty participants with consistent Katakori during the last month were included. We used the patient-elicitation technique, in which the participants were asked to rate the 1) magnitude of disturbance to the elicited activities on an 8-point scale (0-7), and 2) the importance of each activity on an 11-point scale (0-10) in a semistructured interview. A score for each activity was calculated by multiplying the magnitude of the disturbance by its importance, and the score ranged from 0 to 70 . [Results] Among the 186 disturbed activities evaluated in the patient-elicitation technique, 24 coding categories of disturbed activities were identified. The two most prevalent disturbed activities were using a personal computer (62\%), and using a mobile phone or a tablet (52\%). Taking care of children had the highest mean patient-elicitation technique score (66.5). [Conclusion] This study identified 24 conceptual structures of disturbed activities of daily living due to Katakori, which will serve as the foundation for future development of a patient-reported outcome measure for the disability caused by Katakori.

Key words: Disability, Daily activity, Semistructured interview
\end{abstract}

(This article was submitted May 10, 2021, and was accepted Jun. 6, 2021)

\section{INTRODUCTION}

"Katakori" is a unique Japanese term referring to a nonspecific symptom including discomfort or dull pain caused by muscle stiffness around the occiput through the cervical spine to the acromion and scapular area1). In 2019, the Japanese national census demonstrated that Katakori was the most frequent symptom (11.4\% of the whole population) in Japanese women and the second most frequent symptom (5.7\% of the whole population) in Japanese men ${ }^{2}$.

Identifying the effective management strategy of Katakori is required, but it presupposes establishing a valid and reliable outcome measures in the first place. In a recent systematic review that investigated the validity and reliability of the patientreported outcome measure (PROM) for Katakori, it was concluded that none of the PROMs had content validity ${ }^{3)}$.

Content validity is considered the most important psychometric property in the PROM ${ }^{4)}$ and thus should be investigated first. The patient elicitation technique (PET) identifying the most important problems to individual patients through a semistructured interview is a promising measure as a criterion in the investigation of content validity of PROM candidates ${ }^{5-7)}$. Thus, this study aimed to investigate the conceptual structures of disturbed activities of daily living due to Katakori using PET.

*Corresponding author. Hiroshi Takasaki (E-mail: physical.therapy.takasaki@gmail.com)

(C2021 The Society of Physical Therapy Science. Published by IPEC Inc.

(c) (1) $\odot$ This is an open-access article distributed under the terms of the Creative Commons Attribution Non-Commercial No Deriva-

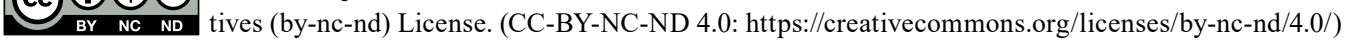




\section{PARTICIPANTS AND METHODS}

An online survey followed by an online semistructured interview for the PET was conducted. Ethical approval for this study was granted by an institutional research ethics committee of the corresponding author (Saitama Prefectural University, No. 20025). Before data collection, the participants provided a written informed consent.

Between August and September in 2020, an online survey link was open on the corresponding author's personal homepage. The homepage was introduced to multiple social network services.

The participants who perceived consistent Katakori during the last month, who were from 18 to 65 years of age, who had knowledge of Japanese as the native language, and who were contactable with email were included. Those who were diagnosed with cognitive, neurological, or respiratory disease and those who were hospitalizing or receiving aged care services were not eligible. Furthermore, the participants who did not participate in the online interview were also not eligible to the study.

The primary outcome measure was the PET. The secondary outcome measures included 1) demographics (age, gender, and body mass index), 2) symptom duration (months) since the last symptom-free month ${ }^{8)}, 3$ ) symptom locations ${ }^{9)}$, 4) pain intensity measured with the 4-item pain intensity measure $(\mathrm{P} 4)^{10)}$, 5) quality of life measured with the Euro QOL 5 Dimensions (EQ-5D), 6) the Japanese Neck Disability Iindex ${ }^{11}$, the 12 -item questionnaire on stiff shoulders with activities of daily living (12-QSSADL) ${ }^{12)}$, and the Japanese version of the 12-item Örebro musculoskeletal screening questionnaire $(\text { OMSQ-12-J) })^{13)}$.

The PET is a semistructured interview ${ }^{5-7)}$, where the four steps were as follows: 1) the participants were asked to spontaneously elicit disturbed activities of daily living due to Katakori as many as possible, 2) the interviewer facilitated identification of further problems, 3 ) the participants were asked to elicit the magnitude of the disturbed activities in terms of the magnitude of difficulty, frequency, or severity on an 8 -point scale $(0=$ not at all difficult, frequent, or severe; $7=$ very difficult, frequent, or severe), and 4) the participants were asked to elicit the magnitude of importance of each activities on an 11-point scale ( $0=$ not at all important; $10=$ most important). Moreover, the elicited activities were ranked in order of importance. A score for each activity was calculated by multiplying the magnitude of the disturbed activity by its importance. The scores for the five most important activity were summed for an overall PET score (0-350). The higher scores indicate more disturbed activity of daily living due to Katakori. The PET has nine dimensions, including role activity, emotional, sleep, mobility, social activities, sports and leisure, personal care, communication, and appearance.

The P4 includes four items with an 11-point numerical rating scale (NRS) for pain intensity. The higher sum scores indicate greater pain intensity $(0-40)$.

The EQ-5D includes five items with five statements for quality of life ${ }^{14)}$. The higher scores indicate better quality of life $(0-1)^{15)}$.

The NDI ${ }^{16)}$ is one of the most common PROMs for neck disability worldwide. The NDI has six statements $(0-5)$ on disability concerning 10 items, including neck pain intensity, personal care, lifting, reading, headaches, concentration, work, driving, sleeping, and recreation. The higher percent scores indicate greater disability due to neck pain.

The 12-QSSADL has been specifically developed for disturbed activities of daily living due to Katakori in Japan from the Roland-Morris Disability Questionnaire ${ }^{12)}$ by modifying the terminology from low back pain to Katakori and response options from the binary scale to 4-point categorical scales and by selecting 12 items through a factor analysis. The higher mean values indicate greater disability due to Katakori.

The OMSQ-12-J includes 12 items with 11-point NRS, which were selected from 21 items through the evaluation of psychometric properties ${ }^{17)}$. The OMSQ-12-J includes 12 constructs: symptom duration (Item 1), bothersomeness for activities of daily living (ADL) (Item 2), magnitude of bothersomeness (Item 3), bothersomeness frequency (Item 4), anxiety (Item 5), depression (Item 6), recovery expectation (Item 7), satisfaction of life (Item 8), kinesiophobia (Item 9), fear avoidance for daily routine or work (Item 10), work or light recreation (Item 11), and ADL and social activities (Item 12). The higher sum scores indicate a higher risk of prolonged recovery from musculoskeletal problems. In our study, each NRS was also used as an indicator for each construct, where the higher scores indicate an unhealthier status.

The participants completed the online survey including the secondary outcome measures. The PET was conducted by two authors using Zoom (Zoom Video Communications, Inc., San Jose, CA, USA) within a few days after the online survey.

The Consensus-based Standards for the selection of health Measurement Instruments (COSMIN) rated 50 participants as adequate sample sizes for the investigation of content validity ${ }^{18,19)}$. Therefore, data collection was continued until the full 50 datasets were obtained.

The three authors individually coded categories of all disturbed activities. Subsequently, the coding categories of activities were created by getting consensuses through discussions with the three authors ${ }^{5-7)}$. When multiple activities were combined into a coding category, then disturbed activities with the highest overall PET scores were retained.

Due to the lack of normal distributions of data, Spearman's $\rho$ correlation coefficients were calculated between the overall PET scores and other secondary outcome measures, including each item of the NDI, the 12-QSSADL, and the OMSQ-12-J, where Pearson's $r$ was used only for gender. Scatter plots between the overall PET scores and overall scores of the NDI and the 12-QSSADL were created to further understand the correlation of the NDI and the 12-QSSADL for the disturbed activity 
of daily living due to Katakori. Correlation coefficients were interpreted as week, $\leq 0.40$; moderate, $>0.4$ and $<0.75$; and strong, $\geq 0.75^{20}$. Moderate or strong correlation was considered meaningful in the current study.

Descriptive analyses were used with mean and standard deviations (SD). Statistical analyses were performed with IBM SPSS (version 25, IBM Corporation, Armonk, NY, USA). Statistical significance was set at 5\%.

\section{RESULTS}

The characteristics of the 50 participants are shown in Table 1. The symptom distributions are shown in Fig. 1. There were four missing data in relation to the driving item in the NDI.

Among 186 disturbed activities elicited in the PET, 23-25 coding categories were initially identified, where the discrepancies were whether laying on the side was included in getting into sleep or not; and whether using a mobile phone was included in using a mobile phone or a tablet or not. Finally, we identified 24 coding categories of disturbed activities, where six activities were combined into the 24 coding categories with a total of 180 categorized activities. The 24 coding categories with the PET score among the 180 disturbed activities of daily living are summarized in Table 2.

Spearman's $\rho$ correlation coefficients between the overall PET scores and secondary outcome measures are presented in Table 3.

\section{DISCUSSION}

This study investigated the conceptual structures of disturbed activities of daily living due to Katakori using PET. The PET demonstrated 24 coding categories of disturbed activities due to Katakori. The most popular two dimensions were communication and mobility. The two most prevalent disturbed activities nominated by the participants were using a personal computer, and using a mobile phone or a tablet. Taking care of children had the highest mean PET scores. However, these items were not specifically included in the NDI and the 12-QSSADL and other PROMs for Katakori severity in a previous review $^{3)}$. Work in the NDI and manual operation (office work) in Item 2 of the 12-QSSADL may indicate using a personal computer in particular for office workers but expressions are ambiguous. Only two items had statistically significant correlations to the overall PET score in the NDI (personal care and reading) (2/10 items) and the 12-QSSADL (Items 2 and 8$)(2 / 12$ items); however, the correlations were $<0.4$ and not acceptable. These findings indicate a need for development of a new PROM for disturbed activities of daily living due to Katakori.

Interestingly, the magnitude of bothersomeness in the OMSQ-12-J had a correlation coefficient of 0.43 to the overall PET score, which indicates an acceptable correlation. Therefore, when a new scale is considered, using the expression of bothersomeness for Katakori disability may be promising.

The current study's participants demonstrated predominant symptoms on the superior part of the trapezius muscles, and the prevalence of symptom locations corresponded to a previous study with a larger cohort (484 nursing staff members) ${ }^{9}$. Furthermore, the overall PET scores statistically significantly correlated with females and anxiety and depression in the OMSQ-12-J subscales, neither age nor body mass index, which corresponded with the previous study with the larger cohort ${ }^{9}$. These findings indicate the samples' validation in the present study.

The overall PET scores were statistically correlated with the EQ-5D, area of symptoms, pain intensity, and recovery expectation. Moreover, these findings indicate that Katakori impacts quality of life, and those with a greater disability tend to have more widely spread and severe pain and less expectation of recovery. In the previous study, it was reported that most people with Katakori (79.8\%) do not consult medical or health practitioners. Furthermore, the previous study demonstrated

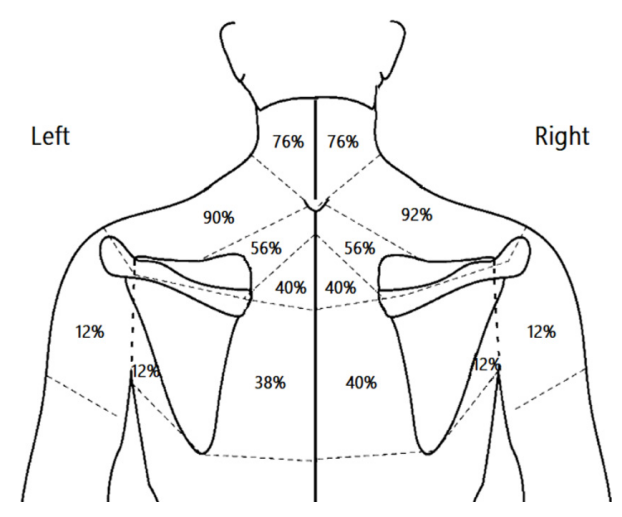

Fig. 1. Location of Katakori symptoms.
Table 1. Characteristics of the 50 participants

\begin{tabular}{lc}
\hline Variables & $\begin{array}{c}\text { Participants } \\
(\mathrm{n}=50)\end{array}$ \\
\hline Age (years) & $26.3 \pm 8.8$ \\
Gender (number of males) & $15.0(30.0)$ \\
Body mass index $\left(\mathrm{kg} / \mathrm{m}^{2}\right)$ & $21.5 \pm 3.1$ \\
Duration of Katakori symptoms (months) & $42.4 \pm 51.8$ \\
Symptom location $(0-14)$ & $6.2 \pm 3.1$ \\
4-item pain intensity measure (0-40) & $13.4 \pm 7.3$ \\
Euro QOL 5 Dimensions (0-1) & $0.7 \pm 0.1$ \\
Japanese version of the 12-item Örebro musculoskeletal & $41.9 \pm 16.3$ \\
screening questionnaire (1-120) & \\
\hline Values are presented with mean \pm standard deviation or number $(\%)$.
\end{tabular}


Table 2. Coding categories with the patient elicitation technique (PET) score among the 180 categorized disturbed activities of daily living due to Katakori

\begin{tabular}{|c|c|c|c|c|c|}
\hline Dimensions & Coding categories & $\begin{array}{c}\text { Number of } \\
\text { participants (\%) }\end{array}$ & $\begin{array}{c}\text { Difficulty, } \\
\text { frequency, or } \\
\text { severity }(0-7)\end{array}$ & $\begin{array}{l}\text { Importance } \\
\quad(0-10)\end{array}$ & $\begin{array}{c}\text { PET score } \\
(0-70)\end{array}$ \\
\hline \multirow[t]{5}{*}{ Communication } & & $39(78)$ & & & \\
\hline & Using a personal computer & $31(62)$ & $4.0 \pm 1.3$ & $7.5 \pm 1.7$ & $30.9 \pm 13.5$ \\
\hline & Using a mobile phone or a tablet & $26(52)$ & $3.9 \pm 1.5$ & $6.2 \pm 2.4$ & $25.7 \pm 16.8$ \\
\hline & Watching a TV & $6(12)$ & $2.7 \pm 1.5$ & $4.3 \pm 2.3$ & $13.2 \pm 11.1$ \\
\hline & Reading & $2(4)$ & $3.5 \pm 0.7$ & $7.5 \pm 0.7$ & $26.0 \pm 2.8$ \\
\hline \multirow[t]{10}{*}{ Mobility } & & $35(70)$ & & & \\
\hline & Sitting for long periods & $16(32)$ & $3.8 \pm 1.3$ & $6.8 \pm 2.1$ & $26.3 \pm 14.2$ \\
\hline & Wearing a backpack & $11(22)$ & $4.4 \pm 1.4$ & $7.1 \pm 2.3$ & $33.1 \pm 18.6$ \\
\hline & Driving & $11(22)$ & $3.2 \pm 1.3$ & $4.8 \pm 2.4$ & $17.4 \pm 12.9$ \\
\hline & Carrying something heavy & $7(14)$ & $4.3 \pm 1.7$ & $5.6 \pm 2.2$ & $26.3 \pm 17.7$ \\
\hline & Reaching the arm and get something at a high place & $3(6)$ & $3.3 \pm 1.2$ & $4.0 \pm 1.0$ & $12.7 \pm 3.1$ \\
\hline & Holding a raised arm position for example holding a strap & $2(4)$ & $4.5 \pm 0.7$ & $5.5 \pm 0.7$ & $25.0 \pm 7.1$ \\
\hline & Standing for long periods & $2(4)$ & $4.0 \pm 1.4$ & $5.5 \pm 0.7$ & $22.5 \pm 10.6$ \\
\hline & Carrying something light including a bag & $2(4)$ & $4.0 \pm 1.4$ & $5.0 \pm 1.4$ & $21.0 \pm 12.7$ \\
\hline & Cycling & $2(4)$ & $3.5 \pm 0.7$ & $6.0 \pm 1.4$ & $20.5 \pm 0.7$ \\
\hline \multirow[t]{5}{*}{ Role activity } & & $23(46)$ & & & \\
\hline & Studying & $12(24)$ & $4.2 \pm 1.8$ & $7.4 \pm 1.9$ & $32.9 \pm 19.2$ \\
\hline & Working for wages & $12(24)$ & $3.5 \pm 1.4$ & $6.7 \pm 2.0$ & $24.6 \pm 14.8$ \\
\hline & Taking care of children & $2(4)$ & $7.0 \pm 0$ & $9.5 \pm 0.7$ & $66.5 \pm 4.9$ \\
\hline & Doing house chores & $2(4)$ & $4.0 \pm 0$ & $6.5 \pm 2.1$ & $26.0 \pm 8.5$ \\
\hline \multirow[t]{3}{*}{ Sleep } & & $19(38)$ & & & \\
\hline & Getting into sleep & $18(36)$ & $3.9 \pm 1.5$ & $6.7 \pm 2.6$ & $29.2 \pm 18.1$ \\
\hline & Laying on the side & $1(2)$ & $1.0^{*}$ & $6.0^{*}$ & $6.0^{*}$ \\
\hline \multirow[t]{3}{*}{ Sport and leisure } & & $8(16)$ & & & \\
\hline & Participating into non-athletic leisure activities & $5(10)$ & $4.6 \pm 1.3$ & $6.6 \pm 2.5$ & $32.6 \pm 19.3$ \\
\hline & Participating into athletic leisure activities & $3(6)$ & $3.0 \pm 2.0$ & $4.3 \pm 2.1$ & $12.3 \pm 11.0$ \\
\hline \multirow[t]{2}{*}{ Emotional } & & $3(6)$ & & & \\
\hline & Poor concentration & $3(6)$ & $3.3 \pm 0.6$ & $6.7 \pm 1.5$ & $22.3 \pm 6.7$ \\
\hline \multirow[t]{3}{*}{ Personal care } & & $2(4)$ & & & \\
\hline & Changing clothes & $1(2)$ & $5.0^{*}$ & $6.0^{*}$ & $30.0^{*}$ \\
\hline & Eating & $1(2)$ & $6.0^{*}$ & $6.0^{*}$ & $36.0^{*}$ \\
\hline Social activities & & $0(0)$ & & & \\
\hline
\end{tabular}

*No standard deviation due to a single value.

Values are presented with mean \pm standard deviation or number $(\%)$.

that those who consulted health practitioners mostly consulted to bone setting ${ }^{9}$, who are trained and allowed to provide medical services only for acute trauma, such as fracture, dislocation, bruise, and sprain in Japan, indicating inappropriate matching of medical services. Further, even when those with Katakori consulted a medical doctor, oral nonsteroidal anti-inflammatory drugs (NSAIDs), NSAID patches, and/or vitamins were often prescribed ${ }^{21)}$, which are not only rarely effective but also dangerous with abuse ${ }^{22,23)}$. Therefore, it is prioritized to establish standardized and valid measures for disturbed activities of daily living due to Katakori in order to identify optimal interventions for disabilities due to Katakori.

The limitation of the current study is related to sampling. The current study used convenience sampling and there would be self-selection bias. However, there were some corresponding findings with the previous study with a larger cohort ${ }^{9)}$, and we believe that our conclusions will not change with a larger cohort.

In conclusion, this study identified 24 conceptual structures of disturbed activities of daily living due to Katakori using the PET, which will be foundation for future development of a patient reported outcome measure for the disability due to Katakori. 
Table 3. Spearman's $\rho$ correlation coefficients between the overall patient elicitation technique (PET) scores and secondary outcome measures in the 50 participants

\begin{tabular}{|c|c|}
\hline Variables & $\begin{array}{c}\text { Spearman's } \rho \text { correlation } \\
\text { coefficients to the overall PET } \\
\text { scores ( } \mathrm{p} \text {-value) }\end{array}$ \\
\hline Age & $-0.14(0.329)$ \\
\hline Gender* & $-0.32(0.026)$ \\
\hline Body mass index & $-0.03(0.813)$ \\
\hline Duration of Katakori symptoms & $0.04(0.780)$ \\
\hline Number of symptom area & $0.35(0.014)$ \\
\hline 4-item pain intensity measure & $0.36(0.011)$ \\
\hline Euro QOL 5 Dimensions & $-0.39(0.005)$ \\
\hline OMSQ-12-J & $0.41(0.003)$ \\
\hline \multicolumn{2}{|l|}{ NDI subscale } \\
\hline Pain intensity & $0.20(0.163)$ \\
\hline Personal care (washing, dressing, etc) & $0.29(0.044)$ \\
\hline Lifting & $0.19(0.194)$ \\
\hline Reading & $0.30(0.038)$ \\
\hline Headache & $0.02(0.870)$ \\
\hline Concentration & $0.20(0.167)$ \\
\hline Work & $0.16(0.260)$ \\
\hline Driving & $0.15(0.320)$ \\
\hline Sleeping & $0.14(0.336)$ \\
\hline Recreation & $0.05(0.748)$ \\
\hline \multicolumn{2}{|l|}{ 12-QSSADL subscale } \\
\hline Item 1 (I stay at home most of the time because of my Katakori.) & $0.26(0.064)$ \\
\hline Item 2 (Because of my Katakori, I find it difficult to do manual operation (office work.) & $0.33(0.019)$ \\
\hline Item 3 (Because of my Katakori, I am not doing any jobs that I usually do around the house.) & $0.05(0.747)$ \\
\hline Item 4 (Because of my Katakori, I lie down to rest more often.) & $0.22(0.119)$ \\
\hline Item 5 (I get dressed more slowly than usual because of my Katakori.) & $0.15(0.315)$ \\
\hline Item 6 (I only hold baggage for short periods of time because of my Katakori.) & $0.26(0.065)$ \\
\hline Item 7 (Because of my Katakori, I try not to reach the arm and get something at a high place.) & $0.15(0.306)$ \\
\hline Item 8 (I find it difficult to raise the arm because of my Katakori.) & $0.30(0.037)$ \\
\hline Item 9 (I have trouble putting on my jacket because of my Katakori.) & $0.20(0.182)$ \\
\hline Item 10 (I sit down for most of the day because of my Katakori.) & $0.17(0.231)$ \\
\hline Item 11 (Because of Katakori, I am more irritable and bad tempered with people than usual.) & $0.23(0.104)$ \\
\hline Item 12 (I stay in bed most of the time because of my Katakori.) & $0.09(0.523)$ \\
\hline \multicolumn{2}{|l|}{ OMSQ-12-J subscale } \\
\hline Symptom duration & $0.05(0.733)$ \\
\hline Bothersomeness for ADL & $0.32(0.022)$ \\
\hline Magnitude of bothersomeness & $0.43(0.002)$ \\
\hline Bothersomeness frequency & $0.31(0.026)$ \\
\hline Anxiety & $0.38(0.007)$ \\
\hline Depression & $0.32(0.024)$ \\
\hline Recovery expectation & $0.44(0.001)$ \\
\hline Satisfaction of life & $0.02(0.919)$ \\
\hline Kinesiophobia & $0.14(0.342)$ \\
\hline Fear avoidance for daily routine or work & $0.04(0.795)$ \\
\hline Work or light recreation & $-0.19(0.190)$ \\
\hline ADL and social activities & $0.13(0.389)$ \\
\hline
\end{tabular}

NDI: Neck Disability Index; 12-QSSADL: 12-item questionnaire on stiff shoulders with activities of daily living; OMSQ-12-J: Japanese version of the 12 -item Örebro musculoskeletal screening questionnaire.

*Pearson's $r$ was calculated (dummy values of 0 for the female and 1 for the male). 


\section{Conference presentation}

A part of this study was presented in the 116th Meeting of Physical Therapy Science, Volume 36 Issue Suppl. 2, https:// doi.org/10.1589/rika.36.S2_1.

\section{Funding and Conflict of interest}

None.

\section{REFERENCES}

1) Yabuki S: Pathogenesis of the neck-shoulder stiffness (Katakori). Rinsho Seikei Geka, 2007, 42: 413-417.

2) Japan Ministry of Health, Labour and Welfare. Comprehensive Survey of Living Conditions 2019. https://www.mhlw.go.jp/toukei/saikin/hw/k-tyosa/k-tyosa19/d1/04.pdf. (Accessed Apr. 19, 2021)

3) Aoki K, Hall T, Takasaki H: Reporting on the level of validity and reliability of questionnaires measuring Katakori severity: a systematic review. SAGE Open Med, 2019, 7: 2050312119836617. [Medline] [CrossRef]

4) Prinsen CAC, Vohra S, Rose MR, et al.: How to select outcome measurement instruments for outcome measurement instruments for outcomes included in a "Core Outcome Set"- a practical guideline. Trials, 2016, 17: 449. [Medline] [CrossRef]

5) Hoving JL, O'Leary EF, Niere KR, et al.: Validity of the neck disability index, Northwick Park neck pain questionnaire, and problem elicitation technique for measuring disability associated with whiplash-associated disorders. Pain, 2003, 102: 273-281. [Medline] [CrossRef]

6) En MC, Clair DA, Edmondston SJ: Validity of the Neck Disability Index and Neck Pain and Disability Scale for measuring disability associated with chronic, non-traumatic neck pain. Man Ther, 2009, 14: 433-438. [Medline] [CrossRef]

7) Buchbinder R, Bombardier C, Yeung M, et al.: Which outcome measures should be used in rheumatoid arthritis clinical trials? Clinical and quality-of-life measures' responsiveness to treatment in a randomized controlled trial. Arthritis Rheum, 1995, 38: 1568-1580. [Medline] [CrossRef]

8) Stanton TR, Latimer J, Maher CG, et al.: Definitions of recurrence of an episode of low back pain: a systematic review. Spine (Phila Pa 1976), 2009, 34: E316-322. [Medline] [CrossRef]

9) Iizuka Y, Shinozaki T, Kobayashi T, et al.: Characteristics of neck and shoulder pain (called katakori in Japanese) among members of the nursing staff. J Orthop Sci, 2012, 17: 46-50. [Medline] [CrossRef]

10) Spadoni GF, Stratford PW, Solomon PE, et al.: The evaluation of change in pain intensity: a comparison of the P4 and single-item numeric pain rating scales. J Orthop Sports Phys Ther, 2004, 34: 187-193. [Medline] [CrossRef]

11) Nakamaru K, Vernon H, Aizawa J, et al.: Crosscultural adaptation, reliability, and validity of the Japanese version of the neck disability index. Spine (Phila Pa 1976), 2012, 37: E1343-1347. [Medline] [CrossRef]

12) Miyazaki J, Kuge H, Sakaguchi S, et al.: Design of a questionnaire on stiff shoulders with activities of daily living as indices: inter-rater reliabilities of questionnaires on shoulder pain and stiff shoulders, and the repeatability of the latter questionnaire. Oriental Medicine and the Pain Clinic, 2014, 44: 2-10.

13) Takasaki H, Gabel CP: Cross-cultural adaptation of the 12-item Örebro musculoskeletal screening questionnaire to Japanese (ÖMSQ-12-J), reliability and clinicians' impressions for practicality. J Phys Ther Sci, 2017, 29: 1409-1415. [Medline] [CrossRef]

14) Shiroiwa T, Ikeda S, Noto S, et al.: Comparison of value set based on DCE and/or TTO data: scoring for EQ-5D-5L health states in Japan. Value Health, 2016, 19: 648-654. [Medline] [CrossRef]

15) van Hout B, Janssen MF, Feng YS, et al.: Interim scoring for the EQ-5D-5L: mapping the EQ-5D-5L to EQ-5D-3L value sets. Value Health, 2012, 15: 708-715. [Medline] [CrossRef]

16) Vernon H, Mior S: The Neck Disability Index: a study of reliability and validity. J Manipulative Physiol Ther, 1991, 14: 409-415. [Medline]

17) Gabel CP, Burkett B, Melloh M: The shortened Örebro Musculoskeletal Screening Questionnaire: evaluation in a work-injured population. Man Ther, 2013, 18: 378-385. [Medline] [CrossRef]

18) Terwee CB, Prinsen CA, Chiarotto A, et al.: COSMIN methodology for evaluating the content validity of patient-reported outcome measures: a Delphi study. Qual Life Res, 2018, 27: 1159-1170. [Medline] [CrossRef]

19) Mokkink LB, de Vet HC, Prinsen CA, et al.: COSMIN risk of bias checklist for systematic reviews of patient-reported outcome measures. Qual Life Res, 2018, 27: 1171-1179. [Medline] [CrossRef]

20) Andresen EM: Criteria for assessing the tools of disability outcomes research. Arch Phys Med Rehabil, 2000, 81: S15-S20. [Medline] [CrossRef]

21) Kitahara M, Shibata M: “Katakori”: a pain syndrome specific to the Japanese. Curr Pain Headache Rep, 2016, 20: 64. [Medline] [CrossRef]

22) Bindu S, Mazumder S, Bandyopadhyay U: Non-steroidal anti-inflammatory drugs (NSAIDs) and organ damage: a current perspective. Biochem Pharmacol, 2020, 180: 114147-114147. [Medline] [CrossRef]

23) Davis A, Robson J: The dangers of NSAIDs: look both ways. Br J Gen Pract, 2016, 66: 172-173. [Medline] [CrossRef] 